\title{
Femtosecond Pulse Laser-oriented Recording on Dental Prostheses: A Trial Introduction
}

\author{
Tetsuo ICHIKAWA ${ }^{1}$, Yoshio HAYASAKI ${ }^{2}$, Keiji FUJITA ${ }^{2}$, Kan NAGAO ${ }^{1}$, Masayo MURATA ${ }^{1}$, \\ Takanori KAWANO ${ }^{1}$ and JianRong CHEN ${ }^{1}$ \\ ${ }^{1}$ Department of Oral \& Maxillofacial Prosthodontics and Oral Implantology, Institute of Health Biosciences, University of \\ Tokushima, 3-18-15 Kuramoto, Tokushima 770-8504, Japan \\ ${ }^{2}$ Department of Optical Science and Technology, Institute of Technology and Science, University of Tokushima, 2-1 Minami- \\ Josanjima, Tokushima 770-8506, Japan \\ Corresponding author, Tetsuo ICHIKAWA E-mail:ichi@dent.tokushima-u.ac.jp
}

Received July 11, 2006/Accepted September 21, 2006

\begin{abstract}
The purpose of this study was to evaluate the feasibility of using a femtosecond pulse laser processing technique to store information on a dental prosthesis. Commercially pure titanium plates were processed by a femtosecond pulse laser system. The processed surface structure was observed with a reflective illumination microscope, scanning electron microscope, and atomic force microscope. Processed area was an almost conical pit with a clear boundary. When laser pulse energy was $2 \mu \mathrm{J}$, the diameter and depth were approximately $10 \mu \mathrm{m}$ and $0.2 \mu \mathrm{m}$ respectively - whereby both increased with laser pulse energy. Further, depth of pit increased with laser pulse number without any thermal effect. This study showed that the femtosecond pulse processing system was capable of recording personal identification and optional additional information on a dental prosthesis.
\end{abstract}

Key words: Femtosecond pulse laser, Titanium, Forensic dentistry

\section{INTRODUCTION}

In massive disasters such as those associated with earthquakes, tsunamis, airplane crashes, and acts of terrorism, forensic dentistry has been shown to be of fundamental importance in medico-legal investigations aimed at identifying human remains. This is because teeth and dental prostheses are the most durable parts of the body, resistant to heat and putrefactive changes ${ }^{1-4)}$. Individual identification through forensic dentistry is performed using tooth morphology, patterns of missing teeth, dental restorations, and restorative materials through radiographic and direct observations.

Alternatively, identification by DNA analysis has also proven to be valuable ${ }^{5,6)}$, although the identification procedure is costly and time-consuming. Then, there are also IC tags (IC chips equipped with a built-in memory) that utilize radio frequency identification, which is an automatic recognition technology that requires no physical contact. Information stored in the memory can be read, updated, or expanded at any time via radio communication signals sent between the reader-writer and the IC tag. In this manner, an IC tag embedded in the body is effective for individual identification ${ }^{7,8}$; ; however, rules and regulations must be in place to protect individual privacy.

Leveraging the usefulness of forensic dentistry, it will be beneficial for dental prostheses to include an identification code. To date, methods to include patient's name in the denture base material ${ }^{9)}$ and personal identification information on metal crowns have been reported. These simple procedures require little time and cost, but also offer limited recording capacity.

To meet the perennial demand for increase of information storage capacity, femtosecond pulse laser systems have been developed. Femtosecond pulse laser processing offers microfabrication on various materials with high spatial resolution ${ }^{10,11)}$. A laser pulse is tightly focused on the material to minimize thermal damage. The purpose of this trial experiment was to explore the feasibility of using femtosecond pulse laser processing to store mass information on dental prostheses.

\section{MATERIALS AND METHODS}

Fig. 1 shows the femtosecond laser processing system used in this study. The femtosecond laser system was composed of a mode-locked Ti: sapphire laser (Spectra Physics, Tsunami) pumped by a diodepumped solid-state continuous-wave green laser (Spectra Physics, Millenia), and a multi-kilohertz pulsed Ti: sapphire regenerative amplifier (Spectra Physics, Spitfire) pumped by a diode-pumped $\mathrm{Nd}$ YLF laser (Spectra Physics, Merlin). The femtosecond laser pulse had a center wavelength of $800 \mathrm{~nm}$ and a pulse width of $\sim 150$ fs. Laser processing diameter was estimated to be $10 \mu \mathrm{m}$. Laser pulse irradiation for a sample was controlled by a mechanical shutter, and laser pulse energy was adjusted by a neutral density (ND) filter. Femtosecond laser 
pulse was then tightly focused on the sample surface via a $40 \times$ microscope objective lens with a numerical aperture (NA) of 0.55. Sample on the motorized stage was observed with a complementary metal oxide semiconductor (CMOS) camera under reflective illumination.

Commercially pure titanium (Grade II) plates were used as the dental material for information storage. The titanium surface was polished by 800 grit sandpaper. Processed surface structure was observed with a reflective illumination microscope (BX-

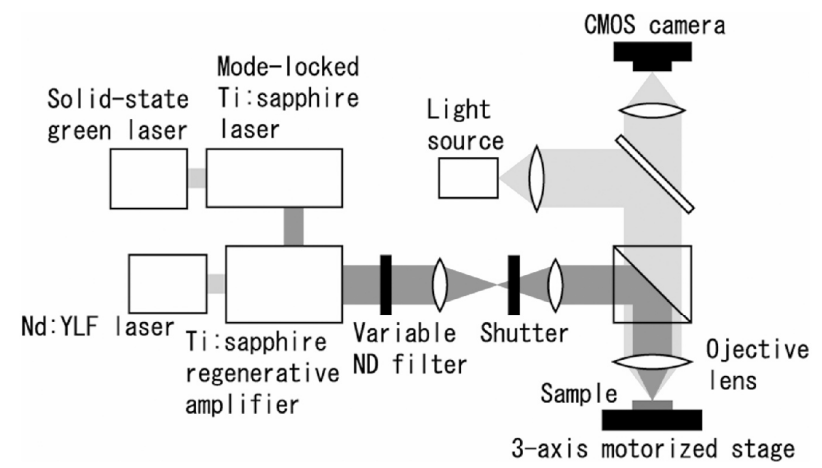

Fig. 1 Experimental setup of the femtosecond laser processing system.
60, Olympus), a scanning electron microscope (SEM; S-4700, HITACHI), and an atomic force microscope (AFM; Dimension-3100, Digital Instruments).

\section{RESULTS}

Fig. 2 shows the influence of laser energy on the surface structure of titanium. The processed structure was an almost conical pit with a clear boundary. When laser pulse energy was $2 \mu \mathrm{J}$, the diameter and depth were approximately $10 \mu \mathrm{m}$ and $0.2 \mu \mathrm{m}$ respectively - whereby both increased with laser pulse energy. It was found that laser pulse energy had a slight thermal effect on surface structure.

Fig. 3 shows the influence of laser pulse number on the surface structure of titanium. Laser pulse irradiated the surface with a frequency of $1 \mathrm{~Hz}$. Depth of pit increased with laser pulse number, whereas the processed morphology was less influenced. Energy emitted from frequent laser irradiation also had less thermal effect on surface structure.

As shown in Fig. 4, the word "TOKUSHIMA" was generated on the surface of a crown made of Ag-Pt-Au alloy (Castwel MC ${ }^{\circledR}$, GC, Tokyo, Japan). Each $10-\mu \mathrm{m}$-square character was sufficiently legible and clear to be read with a microscope.

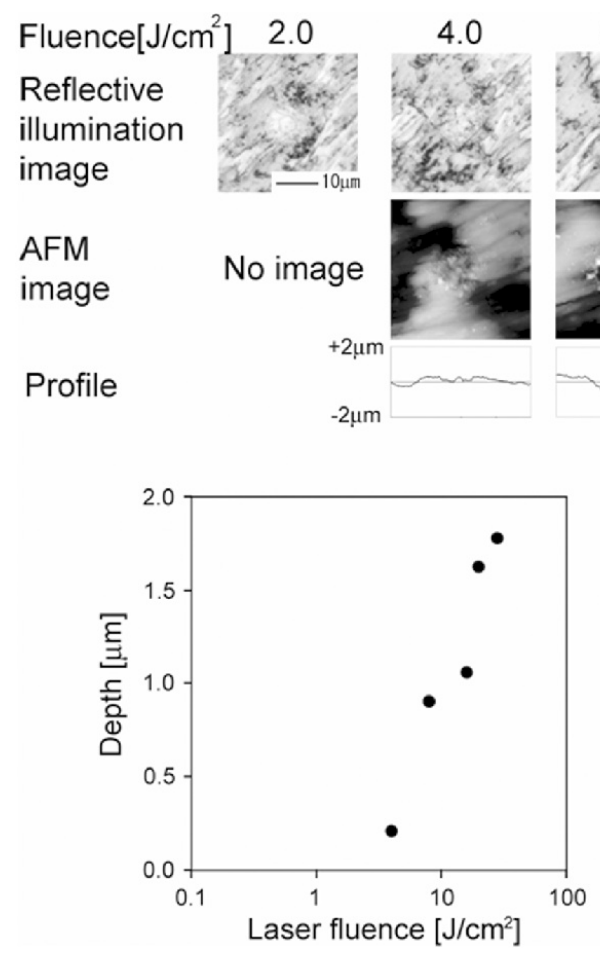

\section{0}
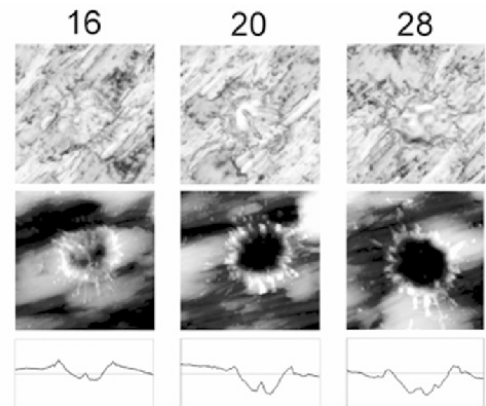

Fig. 2 Influence of laser energy on surface structure. Top images show reflective illumination images, AFM images, and pit profiles by AMF (from top to bottom). Bottom graphs show the relationships of laser fluence $v s$. diameter and depth of the pit by measuring AFM profiles. 

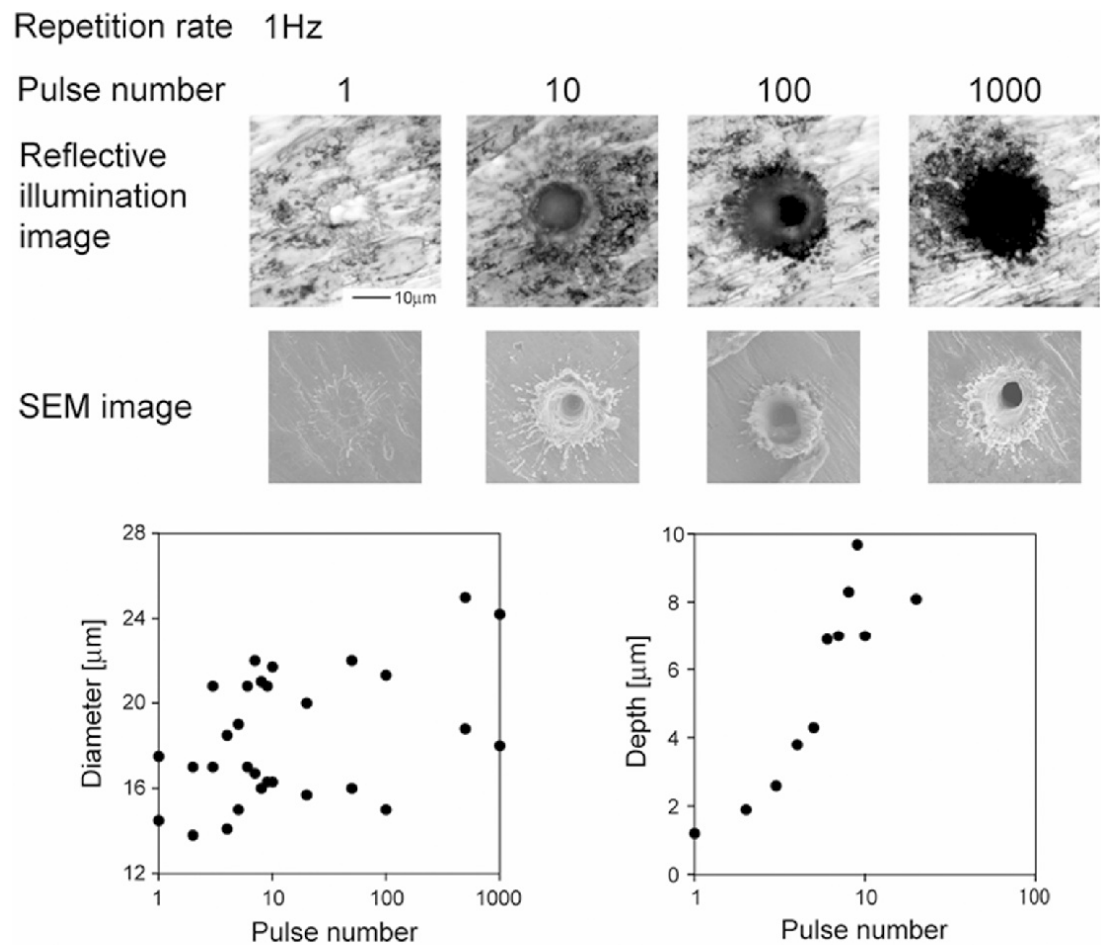

Fig. 3 Influence of laser pulse number on surface structure. Top images show reflective illumination images and SEM images. Bottom graphs show the relationships between laser pulse number vs. diameter and depth of the pit by measuring AFM profiles.

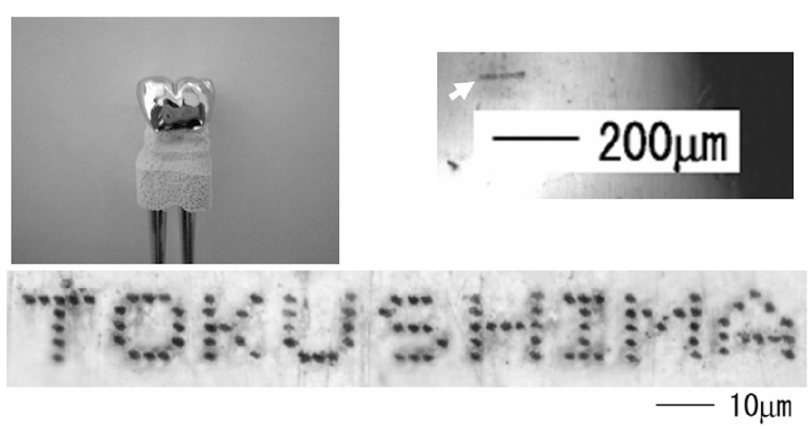

Fig. 4 The word "TOKUSHIMA" was generated on a crown surface. The processing of a dot in the characters is performed with 1000 laser pulses with the diameter of $\sim 1.5 \mu \mathrm{m}$ and the energy of 40nJ.

\section{DISCUSSION}

Laser welding of dental prostheses is performed by means of heat energy ${ }^{12,13)}$. This study demonstrated that a focused femtosecond laser pulse could accurately etch the surface of a dental material with barely any observable thermal effect. In this manner, precise and super-fine processing by femtosecond laser irradiation would cause less distortion of the prosthesis, and hence less clinical problems related to prosthesis fit.

We have also demonstrated that $10-\mu \mathrm{m}$-square characters were successfully etched on the dental material with the focused femtosecond laser processing technique. In other words, the femtosecond pulse processing system could record personal identification and optional additional information on dental prostheses using various two-dimensional and threedimensional optical information storage systems, such as Quick Response (QR) code.

Metal surfaces are often in peril of corrosion and wear ${ }^{14,15)}$. In other words, there is an inherent risk with metal surfaces that laser-etched pits might be blurred out - causing them to be unclear for reading - because of super-fine processing. Therefore, durability testing of femtosecond laser processed surfaces against chemical and physical stresses would need to be conducted, as well as the development of a simple and effective procedure to access recorded/stored information.

\section{REFERENCES}

1) Sognnaes RF. Forensic stomatology. N Engl J Med 1997; 296: 79-85.

2) Bowers CM, Johansen RJ. Digital imaging methods as an aid in dental identification of human remains. J 
Forensic Sci 2002; 47: 354-359.

3) Bowers CM. Forensic dental evidence: an investigator's handbook, $1^{\text {st }}$ ed, Elsevier Academic Press, Amsterdam, 2004.

4) Sholl SA, Moody GH. Evaluation of dental radiographic identification: an experimental study. Forensic Sci Int 2001; 115: 165-169.

5) Deng YJ, Li YZ, Yu XG, Li L, Wu DY, Zhou J, Man TY, Yang G, Yan JW, Cai DQ, Wang J, Yang HM, Li $\mathrm{SB}$, Yu J. Preliminary DNA identification for the tsunami victims in Thailand. Genomics Proteomics Bioinformatics 2005; 3: 143-157.

6) Bowers CM. Problem-based analysis of bitemark misidentifications: the role of DNA. Forensic Sci Int 2006; 159 Suppl 1: S104-S109.

7) Thevissen PW, Poelman G, De Cooman M, Puers R, Willems G. Implantation of an RFID-tag into human molars to reduce hard forensic identification labor. Part 1: Working principle. Forensic Sci Int 2006; 159 Suppl 1: S33-S39.

8) Meyer HJ, Chansue N, Monticelli F. Implantation of radio frequency identification device (RFID) microchip in disaster victim identification (DVI). Forensic Sci Int
2006; 157: 168-171.

9) Thomas CJ. The role of the denture in identification: a review. J Forensic Odontostomatol 1984; 2: 13-16.

10) Takita A, Yamamoto $H$, Hayasaki $Y$, Nishida $N$ Misawa H. Three-dimensional optical memory using a human fingernail. Optics Express 2005; 23: 4560-4567.

11) Takita $A$, Watanabe $M$, Yamamoto $H$, Matsuo $S$, Misawa H, Hayasaki Y, Nishida N. Optical bit recording in a human fingernail. Jpn J Applied Physics 2004; 43: $168-171$

12) Iwasaki K, Ohkawa S, Rosca ID, Uo M, Akasaka T, Watari F. Distortion of laser welded titanium plates. Dent Mater J 2004; 23: 593-599.

13) Baba N, Watanabe I, Tanaka Y, Hisatsune K, Atsuta M. Joint properties of cast Fe-Pt magnetic alloy laserwelded to Co-Cr alloy. Dent Mater J 2005; 24: 550-554.

14) Nakagawa M, Matsuya S, Udoh K. Effects of fluoride and dissolved oxygen concentrations on the corrosion behavior of pure titanium and titanium alloys. Dent Mater J 2002; 21: 83-92.

15) Letic-Gavrilovic A, Scandurra R, Abe K. Genetic potential of interfacial guided osteogenesis in implant devices. Dent Mater J 2000; 19: 99-132. 